\title{
Global Reporting Initiative (GRI) and its Reflections in the Literature
}

\author{
Petr Petera-Jaroslav Wagner*
}

\begin{abstract}
:
Sustainability Reporting Guidelines published by the organization Global Reporting Initiative are gaining on importance and we were investigating whether this trend is also reflected in academic literature and if so, how. We conducted bibliometric analysis based on the Web of Science database to identify key articles, authors, journals and research topics. Results show that the amount of literature dealing with GRI Guidelines is growing. Major journals are Journal of Business Ethics, Corporate Social Responsibility and Environmental Management and Journal of Cleaner Production. High productive authors according to the number of authored or co-authored articles are Brown, H. S., Manetti, G., Evangelinos, K., Skouloudis, A., Searcy, C., Issac, B. and Modapothala, J. R. Research topics of these high productive authors are development of GRI as an institution, development of GRI Guidelines per se, methodologies for assessment of sustainability in organizations and composite indices, methodologies for evaluation and quality assessment of corporate responsibility reports, development of specific (e.g. sector-based) indicators and empirical investigation into indicators used in practice, stakeholder's role in the process of corporate responsibility reporting, assurance for corporate responsibility reports, exploring relation between quality of corporate sustainability disclosure and various variables, empirical content analysis and comparative content analysis of corporate sustainability reports and conceptual issues. We can conclude that the amount of relevant literature is growing and high productive authors and journals are emerging.
\end{abstract}

Key words: Corporate social responsibility reporting; Global Reporting Initiative (GRI); Bibliometric analysis.

JEL classification: M40.

\section{Introduction}

Number of companies publishing corporate responsibility report (hereinafter abbreviated as CR report; in this paper we use this term interchangeably with

* Ing. Petr Petera; Assistant Professor; Faculty of Finance and Accounting, University of Economics, Prague, W. Churchill Sq. 4, 13067 Prague, Czech Republic; <petr.petera@vse.cz>.

doc. Ing. Jaroslav Wagner, Ph.D.; Associate Professor; Faculty of Finance and Accounting, University of Economics, Prague, W. Churchill Sq. 4, 13067 Prague, Czech Republic; <wagner@vse.cz>.

The article is processed as an output of a research project Reporting and utilization of information on sustainable development of firms registered by the Internal Grant Agency of the University of Economics, Prague under the registration number F1/42/2014 (IG107014). 
terms like corporate sustainability report, corporate social responsibility report etc.) has been increasing during last years and according to (KPMG, 2013, pp. 4) "CR reporting has evolved into a mainstream business practice over the last two decades". This development is supported by several causes and it is possible to distinguish non-regulatory motives and regulatory motives for CR reporting. Quite comprehensive overview of goals and benefits of voluntary disclosure can be found e.g. in (Herzig - Schaltegger, 2006, pp. 302-303). Nevertheless (KPMG, 2013, pp. 24) points out that although historically CR reporting has been voluntary, mandatory requirements for $\mathrm{CR}$ reporting are in increase and lead to additional growth of CR reports.

It is understood that (similarly as in the case of financial reporting) stakeholders want CR reports to be comparable (both between companies and also within one company during different time periods) and therefore there are various attempts to standardize these reports both at national and international level. The crucial role in this area is nowadays played by guidelines released by the organization Global Reporting Initiative (hereinafter abbreviated as GRI). For example (KPMG, 2011, pp. 20) stated that the GRI Sustainability Reporting Guidelines (hereinafter abbreviated as GRI Guidelines) were gaining widespread adoption as the de facto global standard for CR reporting already in 2008. Findings in (KPMG, 2013, pp. 31 ) confirmed this observation - e.g. ratio of the world's largest companies referring to the GRI Guidelines increased from $78 \%$ in 2011 to $82 \%$ in 2013.

Hand in hand with the growing importance of the GRI an increased number of academic articles dealing with this topic can be also expected. But as far as we know, bibliometric analysis of relevant literature is still missing. Our goal is to fill this gap by providing a basic bibliometric analysis of articles included in the Web of Science database that in their topic (i.e. in the following fields within a record: "title", "abstract", "author keywords", "keywords plus") mention GRI. More specifically, our aim is to provide both quantitative analysis of the scientific performance (number of articles, key journals, key authors, key articles and their co-citation analysis) and a brief summary of the key research topics.

We are convinced that our findings can help researchers to decide about future research directions as well as about journals where to publish. We also see this bibliometric analysis as a good starting point for conducting yet more comprehensive systematic review of the relevant literature.

Our paper is organized as follows. Part "Data and Methodology" introduces search method and search criteria used for identification of articles, key research questions and framework for analysis. Part "Results and Discussion" contains results of bibliometric analysis as well as brief identification of key research topics and research methods. Part "Conclusion" includes main conclusions and ideas for further research. 


\section{Data and Methodology}

In order to identify key articles, authors and journals dealing with the topic of GRI we used ISI Web of Science database and our search process contained the following steps: First, we used "topic search" (i.e. title, abstract or keywords were targeted). Search query was: TOPIC: (gri) OR TOPIC: ("global reporting initiative") without any additional limitations and as a result we obtained 1248 articles (here we under the term "article" understand all kinds of published information). This search was conducted to date 17. 12. 2014. Second, we excluded all articles in languages other than English. Third, we went through titles and if needed through abstracts of all of these articles to exclude obviously irrelevant ones from our analysis (e.g. because abbreviation "GRI" was used for another topics than Global Reporting Initiative). Finally, we corrected obvious errors in the obtained dataset (e.g. unification of author's names).

After these steps we obtained a dataset of 172 relevant articles for further analysis; for 138 articles (i.e. 80,23\%) we had their full text at our disposal, for 30 articles (i.e. 17,44\%) we had abstract and for 4 articles (i.e. $2,33 \%$ ) we had only basic bibliometric information.

Bibliometric data about these articles became subject of quantitative analysis. Specifically we counted number of articles published in individual years and number of their citations (i.e. number of citations acquired by these articles according to the field "TC" in the Web of Science), number of articles and number of their citations for individual journals, number of articles and number of their citations for individual authors.

We also prepared a co-citation analysis for the most cited articles (originally we wanted to take into account 15 articles with the highest number of citations, but because several articles had the same account of citations, in fact 17 articles were included into analysis). Co-citation analysis is a method for identification of relationship between two documents and it is necessary to distinguish it from bibliographic coupling. While bibliographic coupling links source documents, cocitation links cited documents. The strength of co-citation between the two cited papers is defined by the number of identical citing items, i.e. documents that has cited both earlier articles (Small, 1973, pp. 265). As for interpretation of frequent co-citation, Small (1973, pp. 265-266) suggested that while frequently cited papers represent the key concepts etc., then co-citation depicts relationships between these ideas, respectively measures subject similarity (Small, 1973, pp. 267).

Finally, based on the mentioned analyses and based on the study of relevant articles we briefly summarized key research topics and key research methods. 
Petera, P. - Wagner, J.: Global Reporting Initiative (GRI) and its Reflections in the Literature.

\section{Results and Discussion}

\subsection{Analysis according to the number of articles and citations for individual years}

In Fig. 1 can be found both the number of articles published in individual years and total number of citations that these articles obtained up to date.

\section{Fig. 1: Number of articles and citations in individual years}

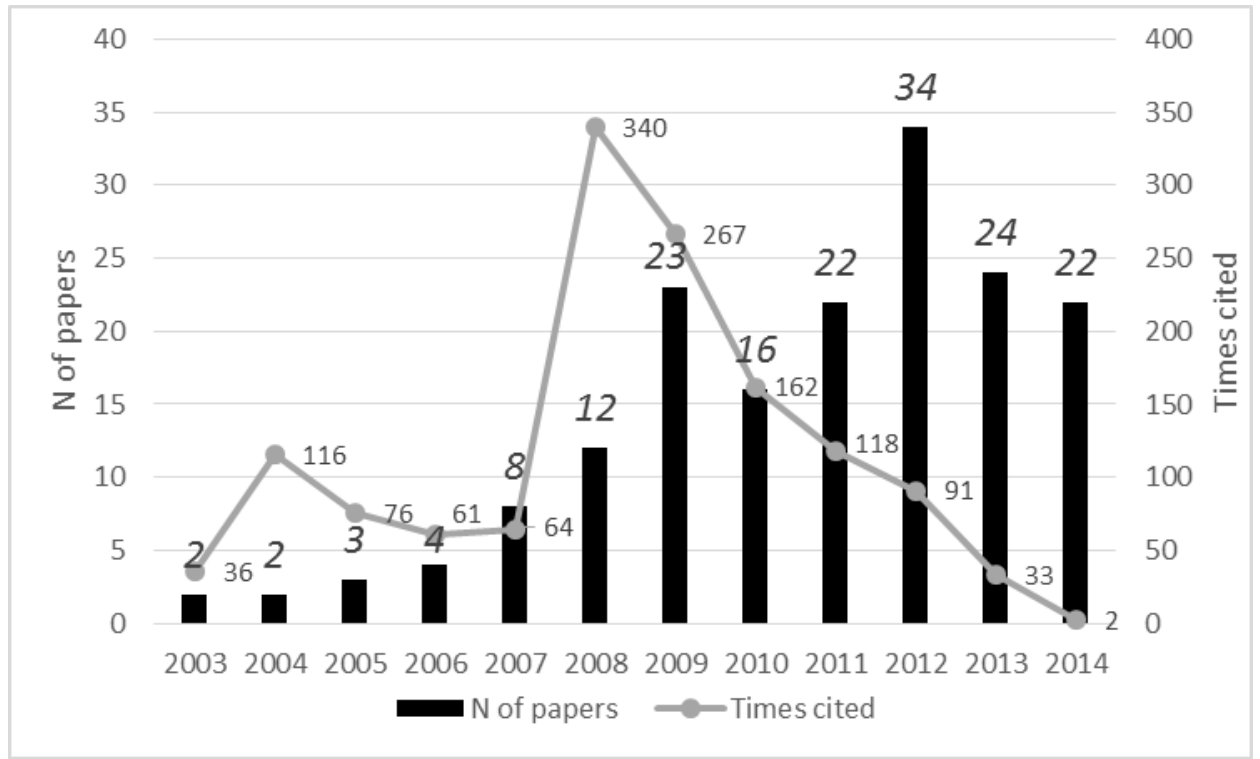

Source: Web of Science, authorial computations and figure preparation.

We consider important to mention that GRI was founded in 1997, the first version (G1) of its guidelines was launched in 2000, the second version (G2) followed in 2002, the third version (G3) in 2006, version G3.1 was launched in 2011 and the latest version of GRI Guidelines (G4) was released in May 2013 (GRI, 2014).

From Fig. 1 it is possible to see that first articles mentioning GRI were published in 2003 ( 2 articles) and that in the last five years (2010-2014) the average number of articles mentioning GRI was 23,6 and median was 22, which is eleventh-times more than in 2003. Moreover the number of articles published in year 2014 may be higher because new articles may be added into Web of Science yet.

It is possible to sum up that results presented in Fig. 1 confirmed our presumption about increasing number of academic articles dealing with GRI and GRI Guidelines. 


\subsection{Analysis according to the number of articles and citations for individual journals}

The goal of this analysis is to identify journals publishing the largest number of articles on GRI-related topics; we included all journals with more than 2 published articles dealing with the GRI, which have more than zero citations. Results of analysis are summarized in Tab. 1.

Tab. 1: Analysis of top journals according to the number of the number of articles

\begin{tabular}{|c|c|c|c|c|c|}
\hline Journal Title & $\begin{array}{l}\text { IF } 2013 \\
\text { with Self } \\
\text { Cites }\end{array}$ & $\begin{array}{c}\text { IF } 2013 \\
\text { without } \\
\text { Self Cites }\end{array}$ & $\begin{array}{c}\text { Issues/ } \\
\text { Year }\end{array}$ & $\begin{array}{c}\mathrm{N} \text { of } \\
\text { articles }\end{array}$ & $\mathbf{N}$ of cit. \\
\hline Journal of Business Ethics & 1,552 & 0,949 & 28 & 15 & 185 \\
\hline $\begin{array}{l}\text { Corporate Social Responsibility } \\
\text { and Environmental } \\
\text { Management }\end{array}$ & 2,054 & 1,071 & 6 & 14 & 127 \\
\hline Journal of Cleaner Production & 3,590 & 2,089 & 18 & 14 & 274 \\
\hline Ecological Indicators & 3,230 & 2,541 & 4 & 6 & 43 \\
\hline $\begin{array}{l}\text { Accounting Auditing \& } \\
\text { Accountability Journal }\end{array}$ & 1,101 & 0,722 & 8 & 4 & 10 \\
\hline $\begin{array}{l}\text { Business Ethics-A European } \\
\text { Review }\end{array}$ & 0,467 & 0,367 & 4 & 3 & 10 \\
\hline Environmental Management & 1,648 & 1,523 & 12 & 3 & 50 \\
\hline Public Money \& Management & 0,636 & 0,393 & 6 & 3 & 25 \\
\hline $\begin{array}{l}\text { Business Strategy and the } \\
\text { Environment }\end{array}$ & 2,877 & 1,658 & 8 & 2 & 9 \\
\hline $\begin{array}{l}\text { Industrial Management \& Data } \\
\text { Systems }\end{array}$ & 1,345 & 0,748 & 9 & 2 & 25 \\
\hline Management Decision & $\begin{array}{l}\text { 3,787(IF } \\
2012)\end{array}$ & $\begin{array}{c}3,461 \\
(\mathrm{IF} 2012)\end{array}$ & 10 & 2 & 13 \\
\hline
\end{tabular}

Source: Web of Science, authorial computations.

From Tab. 1 it is obvious that there are three journals that publish significant number of articles related to the GRI, other journals significantly fall behind.

\subsection{Top rated articles according to the number of their citations}

In Tab. 2 we give an overview of the most cited articles and in Fig. 2 can be found their co-citation network. 
Petera, P. - Wagner, J.: Global Reporting Initiative (GRI) and its Reflections in the Literature.

Tab. 2: Analysis of top articles according to the number of citations

\begin{tabular}{llc|cll}
\hline $\mathbf{N}$ & \multicolumn{1}{c|}{ Article } & $\begin{array}{c}\text { N } \\
\text { cit }\end{array}$ & N & \multicolumn{1}{c}{ Article } & $\begin{array}{c}\text { N } \\
\text { cit }\end{array}$ \\
\hline 1 & Clarkson et al. (2008) & 137 & 10 & Brown et al. (2009a) & 32 \\
2 & Azapagic (2004) & 112 & 11 & Reynolds - Yuthas (2008) & 32 \\
3 & Krajnc - Glavic (2005) & 73 & 12 & Lozano (2006) & 32 \\
4 & Waddock (2008) & 72 & 13 & Lozano - Huisingh (2011) & 27 \\
5 & Brown et al. (2009b) & 48 & 14 & Levy et al. (2010) & 23 \\
6 & Chen - Bouvain (2009) & 39 & 15 & Manetti - Becatti (2009) & 23 \\
7 & Singh et al. (2007) & 39 & 16 & Mudd (2008) & 23 \\
8 & Etzion - Ferraro (2010) & 36 & 17 & Moneva et al. (2007) & 23 \\
9 & Willis (2003) & 36 & & & \\
\cline { 2 - 4 }
\end{tabular}

Source: Web of Science, authorial computations.

Fig. 2 was prepared using software described in Borgatti et al. (2002). Individual articles are represented by the nodes. Size of these nodes matches to the number of citations of a given article and thickness of lines between nodes matches to the number of co-citations between a given pair of articles. Depicted are only cocitation links between articles which are co-cited at least 5 times.

\section{Fig. 2: Co-citation network of highly cited articles}

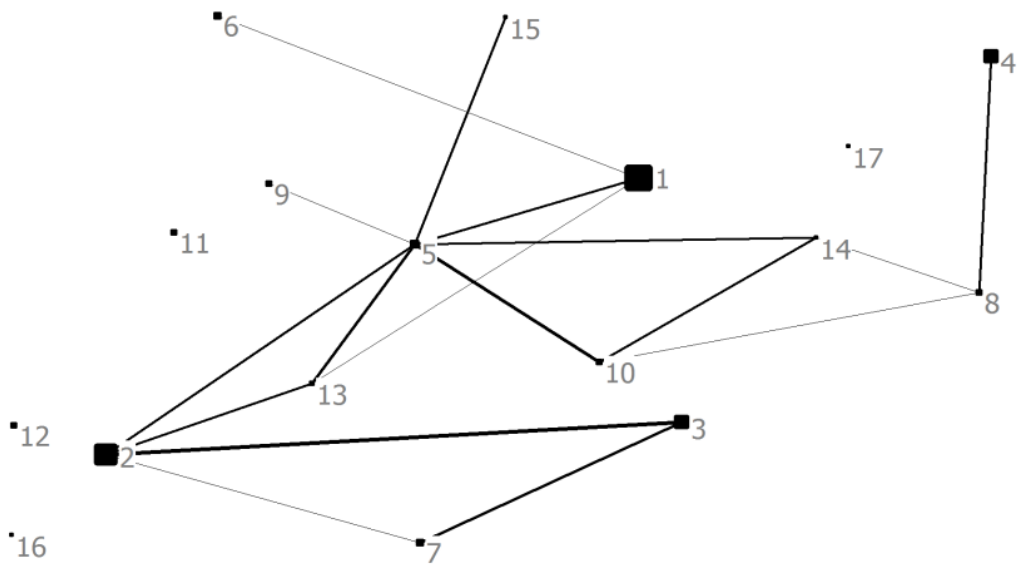

Source: Web of Science, authorial computations and preparation of network.

Co-citation analysis highlights how strong is the relationship between two documents (articles). More specifically, co-citation is a frequency with which two items of earlier literature are cited together by the later literature. Co-citation analysis is supposed to map a research terrain in the sense that the strongest cocitation links should exist between "thematically similar" articles. 
The strongest link (14 co-citations) exists between the articles number 2 and 3, which are dedicated to the issue of sustainability assessment. Both of these articles are linked to the article 7, which dealt with the similar topic; there are 5 cocitations between the articles 2 and 7 and 10 co-citations between the articles 3 and 7. The article 13 also dealt with the sustainability assessment and has 6 cocitations with the article 2 .

The second strongest link ( 11 co-citations) exists between the articles number 5 and 10, which were authored by Brown and addressed the issue of the GRI as an institution (history, importance, politics etc.). In fact, the article number 5 stands in the center of the co-citation network and has the largest number of strong cocitations with the others. On the one hand, there are co-citations of the article 5 with the articles dealing with similar issues, which are numbered 9 (5 co-citations) and 14 (6 co-citations). On the other hand, there are also strong co-citations of the article number 5 with the articles number 13 (10 co-citations), 15 (8 co-citations), 1 (8 co-citations) and 2 (6 co-citations). These strong co-citation links are difficult to explain (for more detailed discussion of this issue see paragraph below). Last but not least, the article number 5 is via articles 10 and 14 linked also with thematically similar articles 8 and 4. Finally, co-citation link of the strength 5 is also between articles 1 and 6 and articles 1 and 13. Isolated (i.e. without 5 or more co-citations with the other articles) are the articles number 11, 12, 16 and 17.

To better understand the described co-citation patterns, we performed detailed study of the 17 selected articles. This research confirmed that there are two main topics and several smaller ones.

The first main topic is represented by the articles dealing with sustainability assessment methodology in general and especially with the development of indexes measuring sustainability performance in a more integrated manner than by myriads of indicators. Into this group of articles belong nodes numbered 2, 3, 7, 12 and 13.

The second main topic is represented by the articles dealing with the GRI as an institution (history, institutional structure, development, politics etc.) as well as with development of the GRI Guidelines per se (nodes number 4, 5, 8, 9, 10 14).

Finally, there are the articles that are oriented towards various topics. Clarkson et al. (2008), in Fig. 2 represented by node number 1, addressed relation between environmental performance and environmental disclosure and developed an index for measuring the extent of a firm's environmental disclosure. Chen and Bouvain (2009), in Fig. 2 represented by node number 6, investigated international convergence of sustainability reporting. Reynolds and Yuthas (2008), in Fig. 2 represented by node number 11, in their unique conceptual article applied Habermas' theory of communicative action to analysis of various approaches to corporate social responsibility management and reporting. Manetti and Becatti 
Petera, P. - Wagner, J.: Global Reporting Initiative (GRI) and its Reflections in the Literature.

(2009), in Fig. 2 represented by node number 15, addressed practically important topic of assurance for sustainability reports. Mudd (2008), in Fig. 2 represented by node number 16, dealt with specific topic of appropriate indicators for reporting on water resources and provided critique of the GRI Guidelines in this area. Moneva et al. (2007), in Fig. 2 represented by node number 17, investigated whether strategic commitment of a company (to its stakeholders vs to its shareholders) was positively linked to a company's social and financial performance.

We can conclude that our co-citation analysis and a more detailed content analysis of the 17 most cited articles brought compatible results with one major exception. The article number 5 (Brown et al., 2009b) was intensively co-cited with several articles without sufficient "subject similarity" and we propose the following explanation. Brown et al. (2009b) in their article provided comprehensive information about the GRI (history, importance etc.) and authors who wanted to mention this topic in their articles (whatever was their main subject) cited (next to the articles relevant from the viewpoint of their main subject) also Brown's work. We can therefore conclude that our investigation identified key topics of top-cited articles and confirmed assumption that co-citation analysis maps a research terrain by highlighting the strongest co-citation links between "thematically similar" articles.

\subsection{High productive authors (analysis according to the number of articles and citations of individual authors)}

The goal of this analysis is to identify the most productive and most cited authors as well as key research topics.

First, for individual authors we counted the number of citations of their articles as well as number of their articles by taking into account only the first/leading author of every article; i.e. only the leading author of a given article was accredited a number of citations pertaining to the given article. In Tab. 3 are enlisted ten most cited authors as well as ten authors with the highest number of articles. In the case of the same value of main sorting criterion, we used the second criterion to exclude redundant authors if possible. 
Tab. 3. Analysis of top authors (into account is taken only the first author of the article) according to the number of citations and according to the number of articles

\begin{tabular}{|c|c|c|c|c|c|}
\hline \multicolumn{3}{|c|}{$\begin{array}{c}\text { Authors sorted primarily according to the } \\
\text { number of citations }\end{array}$} & \multicolumn{3}{|c|}{$\begin{array}{l}\text { Authors Sorted primarily according to the } \\
\text { number of articles }\end{array}$} \\
\hline Author & $\mathbf{N}$ of cit. & $\mathbf{N}$ of $\mathrm{A}$ & Author & $\mathbf{N}$ of $A$ & $\mathbf{N}$ of cit. \\
\hline Clarkson, P. M. & 152 & 2 & Lozano, R. & 3 & 62 \\
\hline Azapagic, A. & 112 & 1 & Manetti, G. & 3 & 42 \\
\hline Brown, H. S. & 80 & 2 & Skouloudis, A. & 3 & 31 \\
\hline Krajnc, D. & 73 & 1 & Dingwerth, K. & 3 & 16 \\
\hline Waddock, S. & 72 & 1 & Modapothala, J. R. & 3 & 1 \\
\hline Lozano, R. & 62 & 3 & Clarkson, P. M. & 2 & 152 \\
\hline Manetti, G. & 42 & 3 & Brown, H. S. & 2 & 80 \\
\hline Chen, S. & 39 & 1 & Rasche, A. & 2 & 25 \\
\hline Singh, R. K. & 39 & 1 & Asif, M. & 2 & 8 \\
\hline Etzion, D. & 36 & 1 & Perez-Batres, L. A. & 2 & 8 \\
\hline Willis, A & 36 & 1 & & & \\
\hline
\end{tabular}

Source: Web of Science, authorial computations

Second, for individual authors we counted the number of citations of their articles as well as number of their articles by taking into account all authors of every article; i.e. all authors (not only the first/leading author) of a given article were accredited a number of citations pertaining to the given article. Consequently we sorted authors in descending order and in Tab. 4 are enlisted ten most cited authors as well as ten authors with the highest number of articles with non-zero citations. In the case of the same value of main sorting criterion, we used the second criterion to exclude redundant authors if possible.

Tab. 4: Analysis of top authors (into account are taken all authors of the article) according to the number of citations and according to the number of articles

\begin{tabular}{|c|c|c|c|c|c|}
\hline \multicolumn{3}{|c|}{$\begin{array}{c}\text { Authors sorted primarily according to the } \\
\text { number of citations }\end{array}$} & \multicolumn{3}{|c|}{$\begin{array}{c}\text { Authors Sorted primarily according to the } \\
\text { number of articles }\end{array}$} \\
\hline Author & $\mathbf{N}$ of cit. & $\mathbf{N}$ of $\mathrm{A}$ & Author & $\mathbf{N}$ of $\mathrm{A}$ & $\mathbf{N}$ of cit. \\
\hline Clarkson, P. M. & 152 & 2 & Brown, H. S. & 4 & 109 \\
\hline $\mathrm{Li}, \mathrm{Y}$. & 137 & 1 & Manetti, G. & 4 & 42 \\
\hline Richardson, G. D. & 137 & 1 & Evangelinos, $\mathrm{K}$. & 4 & 32 \\
\hline Vasvari, Florin P. & 137 & 1 & Skouloudis, A. & 4 & 32 \\
\hline Azapagic, A. & 112 & 1 & Searcy, C. & 4 & 28 \\
\hline Brown, H. S. & 109 & 4 & Issac, B. & 4 & 1 \\
\hline de Jong, M. & 103 & 3 & Modapothala, J. R. & 4 & 1 \\
\hline Krajnc, D. & 76 & 2 & de Jong, M. & 3 & 103 \\
\hline Glavic, $\mathrm{P}$. & 73 & 1 & Lozano, R. & 3 & 62 \\
\hline Waddock, S. & 72 & 1 & Rasche, A. & 3 & 46 \\
\hline
\end{tabular}

Source: Web of Science, authorial computations.

The second approach is more fair toward the second and other authors, nevertheless resulting order of authors according to the number of citations of their 
Petera, P. - Wagner, J.: Global Reporting Initiative (GRI) and its Reflections in the Literature.

articles may be significantly affected by highly cited articles with relatively numerous co-authors and it is the case in our analysis - e.g. Li, Y., Richardson G. D. and Vasvari, F.P. are in 2nd-4th position thanks to their co-authorship of article (Clarkson et al., 2008).

The rest of this chapter briefly introduces key research topics of the aforementioned highly productive authors and thus expands overview of topics that can be found in the chapter dedicated to the top rated articles according to the number of their citations.

The first topic is the GRI as an institution and development of the GRI Guidelines per se. This topic was addressed in articles (Brown et al. 2009a; Brown et al. $2009 \mathrm{~b})$. These articles critically analyzed evolution of the GRI through the lens of institutional theory and identified several issues caused by the institutional logic involved in the process of the GRI evolution. Probably the most crucial issue, which was identified by these articles, was according to our opinion the fact that by developing the GRI within the existing institutional infrastructure, the GRI's founders to a large extent only reproduced the existing power relations (with dominant global companies, financial institutions, and international consultancies) and failed to mobilize weaker players (civil society, NGOs etc.). Another important issue mentioned in these articles was insufficient attention dedicated to quality control both of reports and process used to produce these reports. Brown was also a second author of another article on institutionalization of sustainability reporting with central focus on the GRI as a prominent example of institutional entrepreneurship (Levy et al., 2010). Findings in Levy's article are quite perturbing (e.g. low number of organizations reporting according to GRI, distrust of NGOs of reports prepared according to the GRI Guidelines because of insufficient company and sector specific information etc.), nevertheless we believe that recent development at least partially weakened concerns invoked by this article (e.g. growing numbers of organizations reporting according to the GRI Guidelines, stronger emphasis on assurance), but there are still many issues that have to be solved. Waddock (2008) dealt with the institutional infrastructure for corporate responsibility, nevertheless her article was not GRI-focused and provided substantially broader view on the researched area. By highlighting and systematically classifying institutional infrastructure around sustainability issues, this article illustrates how this infrastructure shapes responsible behavior of organizations (including reporting on corporate ecological, social etc. responsibilities). Etzion and Ferraro (2010) investigated institutionalization of sustainability reporting through analysis of role of analogies in development and rise of the Global Reporting Initiative organization. An important contribution made by Etzion and Ferraro (2010) to the institutional theory is proposition that analogy may affect institutionalization processes via two mechanisms. First, analogy promotes legitimacy by emphasizing similarity of a new institution with 
the existing institutions; this approach is usually used in initial phases to gain support for the new institution. Second, analogy serves as a tool for highlighting differences. The second function of analogy enables avoids undesirable replication of the logics of the source institutions; this approach is usually utilized later and may lead to substantial difference of the new institutional structure in relation to its analogical source. Willis (2003) in his short and non-critical article summarized benefits of reporting according to the GRI Guidelines for socially responsible investments, gave review of basic ideas underlying first versions of the GRI Guidelines and exposed hopes and possible directions of further development.

The second topic is represented by methodologies for assessment of sustainability in organizations and composite indices (in articles on this topic are often used terms like "sustainability assessment methodologies", "composite index", "integrated index", "scoring systems in corporate sustainability reporting" etc.). Krajnc and Glavic (2005) expressed critique of utilization of "too many indicators" and developed a "composite sustainable development index" for assessment of sustainable development of a company. Lozano in his works (Lozano, 2006; Lozano - Huisingh, 2011; Lozano, 2013) dealt with the problem of composite indicators and also with condensed graphical reporting of sustainable performance. In the first mentioned article are the GRI Sustainability Guidelines taken as a basis on which is developed tool for assessment and reporting of sustainability performance in higher education institutions and provided is also critique of too large number of indicators included in the GRI Guidelines (which complicates especially long-term comparison and benchmarking). The second paper provided a sustainability categorization based on three "traditional" dimensions (economic, environmental, and social) as well as on time dimension (short-term, long-term) and all these dimensions inter-relate; article offered also a brief overview of approaches to construction of composite indexes. The third article dealt with inter-linkages among various dimensions of sustainability and provided several ideas for further research. Singh's key research topic in the area of sustainability reporting is also development of sustainability performance indices and sustainability assessment methodologies in general, see e.g. (Singh et al., 2007). We can summarize that construction of composite indices is a very actual and important topic, which is insufficiently addressed within the GRI Guidelines (this fact is also mentioned by some of the discussed articles). It would be interesting to monitor the future development in the area of assessment of sustainability performance and the relative importance of GRI reports in this assessment. It is known that some assessment methodologies use GRI reports for evaluation of sustainability performance, but others (e.g. Dow Jones Sustainability Indices) use other methodologies and do not rely solely on the GRI reports.

The third topic is methodologies for evaluation and quality assessment of corporate responsibility reports. This topic, which is interlinked with the previous 
one, was addressed in four works by Skouloudis and Evangelinos (Evangelinos et al., 2009; Skouloudis et al. 2009; 2010; 2012), where can be found an overview of various scoring systems for sustainable reporting and also principles (but not details) of a scoring system developed by the authors themselves. This new scoring system takes as a basis the GRI Guidelines version 2 and includes 142 indicators of the GRI Guidelines, which serve as separate measurable parameters; authors applied their scoring system to the corporate responsibility reports of various organizations. Skouloudis et al. (2009) highlighted that their assessment methodology did not directly evaluated corporate performance in the area of sustainability, but concentrated solely on the reporting practices and evaluated the breadth and depth of reported issues. High score therefore does not mean that the corporation has high performance in the area of issues related to sustainability. The total score is influenced both by breadth and depth of a report and so two corporations may obtain the same score, but components of this score may be substantially different; high total score per se does not guarantee that the report is balanced or inclusive - more detailed information about components of the total score is needed. Well, considering that nowadays there is already version 4 of the GRI Guidelines, mentioned scoring system may serve as an inspiration for development of an updated scoring systems based on the GRI G4.

Approach to scoring sustainability reports through techniques of text mining and data mining was applied e.g. in Modapothala et al. (2010). It is important to notice that issue of selecting (or even developing) a scoring system for sustainability reporting appears also in the articles, which are dedicated to seeking relations e.g. between quality of corporate sustainability reporting and some other variable (e.g. environmental performance, social performance, value of a company etc.).

The fourth topic (which is closely related to the second topic) is a development of specific (e.g. sector-based) indicators and is addressed e.g. in Azapagic (2004), where are the GRI Guidelines utilized for development of framework of indicators specific for mining and minerals industry sector. From the point of view of utilized indicators we consider important the fact that included are also "integrated" indicators, which combine two or more aspects of sustainability into one metric and doing so enable more holistic view. Because of its comprehensiveness the framework is more suitable for larger corporations and Azapagic (2004) notes that further work is needed to develop a more simplified framework of indicators for smaller organizations because these organizations play an important role in the mining sector efforts to achieve sustainability.

The fifth topic is stakeholder's role (engagement) in the process and assurance of corporate responsibility reporting. Manetti (2011) dealt with problem of stakeholder engagement by comparing postulates about importance of such engagement given in literature with practice. Manetti (2011) on the basis of his 
findings concluded that among corporations prevailed practices of stakeholder management than real engagement (e.g. because of low involvement of stakeholders in defining content of sustainability reports, rare adoption of standards related to engagement etc.). Manetti and Toccafondi (2012) in their exploratory study addressed the importance of stakeholder engagement during preparation of sustainability reports and during assurance process and provided an empirical content analysis of 160 assurance statements from the viewpoint of stakeholders involvement with mixed results (e.g. stakeholders are engaged in the process, but there is a low level of external stakeholders, high incidence of unqualified opinion etc.). The issue of credibility of corporate sustainability reports (without the direct link to stakeholders engagement) was addressed in Manetti and Becatti (2009) who highlighted that there was a credibility gap because of which sustainability reports were little used by the traditional target users like shareholders, lenders, customers etc. The strategic role in bridging this gap belongs to assurance services providers. Manetti and Becatti (2009) also gave an analysis and critique of the current international standards and suggested numerous improvements especially concerning the standard ISAE 3000 (International Standard on Assurance Engagements). Dingwerth and Eichinger (2010) explored whether reporting under the GRI Guidelines empower stakeholders (the users of disclosed information) and provided critical view on this topic. Their main conclusions were as follows: first, despite the fact that the explicit definition of "transparency" by the GRI Guidelines acknowledged the transformative and empowering potential of corporate transparency, analysis of real GRI's external communications showed that in practical communication the GRI used definitions, which gave much lesser role to empowerment; second, implementation of principles like value, accessibility, comprehensibility, and comparability was only weakly monitored; although analyzed reports contained lots of information related to the sustainability, the information remained incomparable; last but not least, intermediaries (like civil society organizations) were virtually absent, i. e. did not use information from corporate GRI reports to realize the empowerment potential of disclosure.

The sixth topic is represented by articles aimed at finding relation between quality of corporate sustainability disclosure and various variables. For example in article (Clarkson et al., 2008) is explored the topic of "relation between environmental performance and environmental disclosure" and developed is also "composite index" for measuring the extent of a firm's disclosure (in the area of environment). Clarkson et al. (2011) concluded that there was a positive association between environmental performance and the level of voluntary environmental disclosures. Their result is consistent with the predictions of the economics disclosure theory (which claims that organizations with superior environmental performance will report their supremacy by pointing to objective environmental performance 
Petera, P. - Wagner, J.: Global Reporting Initiative (GRI) and its Reflections in the Literature.

indicators which are difficult to mimic by inferior type firms; on the contrary, inferior performers will disclose only little or any information on their environmental performance). The same index was used for analysis of the mentioned relation in case of a different sample of organizations by Clarkson et al. (2011).

The seventh topic includes various empirical articles, usually descriptive in their nature, which are typically dedicated to the content analysis of corporate sustainability reports. Chen and Bouvain (2009) compared corporate responsibility practices among a sample of leading companies in four countries (US, UK, Australia and Germany) by analyzing corporate social reports on web sites and checked whether membership of Global Compact made a difference to corporate social reporting and overcame industry and country specific factors. They concluded that membership in Global Compact had influence on corporate social reporting (but only in areas of environment and workers) and that organizations from different countries significantly varied both in the extent to which they promote corporate social responsibility and in issues that they emphasized. PerezBatres et al. (2010) provided an empirical analysis of influence of different factors (especially of normative pressures, i.e. existence of greater European influence upon a given company and mimetic pressures, i.e. whether a firm is listed on the NYSE) on reporting of Latin American corporations according to the GRI Guidelines and on registration of these companies in Global Compact. The study concluded that the influence of both these pressures was significant. Perez-Batres et al. (2012) addressed problem of factors influencing choice of symbolic vs substantive codes of conduct, nevertheless we feel obliged to notice that methodology chosen in this article is from our viewpoint controversial. Searcy and Buslovich (2014) used interview with 35 Canadian corporations as a method to obtain answers to two basic research questions: "How are sustainability reports developed by corporations?" "How are sustainability reports used internally by corporations?" Authors concluded that the content of sustainability reports was influenced by sustainability reporting standards, internal evaluation and a variety of other methods. While 5 corporations prepared fully integrated reports, 15 organizations included information on sustainability in their annual reports. As for involvement of external stakeholders, majority of companies considered stakeholder input. In total 25 organizations used for preparation of report only internal personnel, 10 organization used also some external subjects. Data collection was usually lead by sustainability departments and conducted by a number of different individuals. Internally were reports used for various purposes (e.g. enhancing employee awareness and engagement and also as an internal reference tool. Roca and Searcy (2012) in their article conducted a detailed content analysis of 94 Canadian corporate sustainability reports to identify reported indicators. From the viewpoint of usage of the GRI Guidelines is important 
finding that of the 94 reports, 31 included indicators explicitly identified as GRI indicators (version 3 of the GRI Guidelines). Asif et al. (2013) dealt with descriptive content analysis of corporate reporting by Dutch companies. Thorne et al. (2014) investigated motives for issuing standalone reports in the case of Canadian firms. In accordance with other similar studies, Thorne et al. (2014) concluded that standalone CSR reports were published by larger firms and that reports were issued primarily because of external scrutiny by stakeholders or regulations regardless of actual corporate social responsibility performance.

Finally, highly productive authors addressed also conceptual problems. Gilbert and Rasche (2008) provided classification and analysis of different standardized ethics initiatives (which were operationally defined as voluntary standards defining norms and procedures for organizational behavior in relation to social and environmental issues) from a point of view of stakeholder theory and gave insights into strengths and weaknesses of the individual ethic initiatives. Rasche (2009) developed a model for systematic comparison and analysis of accountability standards. More specifically, Rasche (2009) reminded classification of the existing initiatives according to the mechanisms, which they use to hold firms accountable (policy, accounting, auditing, and reporting) and according to the focus of their rules (social, environmental, and economic) and pointed out that this classification did not provide sufficient information about standards. Rasche therefore introduced a new framework, which was meant not to substitute but to supplement the classification mentioned above. This new framework was based on the idea that standards can be discussed with regard to the content of their rules, the processes, which are needed for implementation of these rules and the industry and geographic context in which can the rules be applied. The framework is supposed to be used as a tool for analysis and comparison of sustainability standards. In another conceptual paper Rasche (2010) analyzed limits of corporate responsibility standards (GRI, Fair Labor Association workplace code and especially Social Accountability 8000) through the lens of Derrida's aporias of justice (i.e. "undecidable situation in which we cannot turn to or justify one side of an opposition"; Rasche, 2010, pp. 180). Another conceptual topic was addressed in Asif et al. (2011), where was discussed compatibility of sustainability and existing business excellence models.

Specific topic is "critique" of the GRI as an institution or the GRI Guidelines per se. It is above the scope of this paper to address this topic systematically and comprehensively, nevertheless we feel that critiques are numerous and deserve systematization. Here we only sum up that critique is often aimed at insufficient inclusion of some groups of stakeholders into the process of Guidelines preparation, insufficient guidelines for assurance of reports, insufficient mechanisms for control over respecting basic rules underlying the GRI Guidelines [e.g. weak monitoring whether principles of value, accessibility, 
Petera, P. - Wagner, J.: Global Reporting Initiative (GRI) and its Reflections in the Literature.

comprehensibility, and comparability are really implemented (Dingwerth and Eichinger, 2010, pp. 91)], unclear instructions about setting boundaries of corporations (Archel et al., 2008), existence of too many indicators and lack of composite indicators as well as lack of inter-linking of various dimensions of sustainability.

\subsection{Brief summary of key research methods}

Dominant research method in the studied field is quantitative and qualitative content analysis (aimed e.g. at corporate sustainability reports, the GRI Guidelines per se or at various documents of the GRI as an organization). We noticed usage of various software tools for qualitative content analysis (e.g. ATLAS.ti, Leximancer, MAXQDA and NVivo).

As for research design, very broad mix of techniques is used, e.g. case studies, multiple case studies, longitudinal case studies, interviews, surveys and mixed methods are used.

Finally, in the area of developing composite indexes we can find methods like Delphi method, fuzzy Delphi method, various Multi-criteria decision-making (MCDM) methods, especially AHP (analytic hierarchy process) and FAHP (fuzzy analytic hierarchy process).

\section{Conclusion}

Bibliometric analysis of the literature obtained through search in the Web of Science database revealed that the number of articles dealing with the GRI during years 2002-2014 significantly increased.

We identified key journals (especially Journal of Business Ethics, Corporate Social Responsibility and Environmental Management and Journal of Cleaner Production), key authors and key articles and consequently we discussed key topics. Last but not least, we gave a brief overview of research methods used in the studied area.

Based on our knowledge of the discussed topic, we consider bibliometric analysis of the literature, which we provide in this paper, to be a good representation of the current literature on the discussed topic in the sense that we identified key authors, journals and topics. Nevertheless we are aware of limitations of our research method. First, we analyze solely the literature included in the Web of Science database (to work only with highly respected sources). Second, we could miss articles that do not mention GRI in their topic (title, abstract, keywords). Finally, our analysis is aimed primarily at the most cited articles, which limits the space dedicated to the newest literature (which could not obtain enough amount of citations) although this disadvantage is weakened by discussing some works 
written by highly productive authors with higher number of articles dealing with the GRI regardless the number of citations.

In the context of the previous text we would like to provide at least two ideas for the further research. First, we propose that due to the growing amount of literature dealing with the GRI it is time to prepare systematic literature review on this topic, which would comprehensively collect, analyze and assess relevant literature. We are convinced that bibliometric analysis provided in this paper is a strong basis for such systematic review. Second, because of the considerable lack of literature on the newest version of the GRI Guidelines (version 4) we suggest to aim further research on the topic how are the latest Guidelines implemented in practice (through large-scale quantitative and qualitative content analysis of reports prepared according to the GRI G4).

\section{References}

Archel, P., Fernandez, M., Larrinaga, C., 2008. The organizational and operational boundaries of triple bottom line reporting: A survey. Environmental Management 1, 106-117.

Asif, M., Searcy, C., Garvare, R., Ahmad, N., 2011. Including sustainability in business excellence models. Total Quality Management \& Business Excellence 7, 773-786.

Asif, M., Searcy, C., dos Santos, P., Kensah, D., 2013. A Review of Dutch Corporate Sustainable Development Reports. Corporate Social Responsibility and Environmental Management 6, 321-339.

Azapagic, A., 2004. Developing a framework for sustainable development indicators for the mining and minerals industry. Journal of Cleaner Production 6, 639-662.

Borgatti, S. P., Everett, M. G., Freeman, L. C., 2002. Ucinet for Windows: Software for social network analysis. Harvard, MA: Analytic Technologies.

Brown, H. S., de Jong, M., Lessidrenska, T., 2009a. The rise of the Global Reporting Initiative: a case of institutional entrepreneurship. Environmental Politics 2, 182-200.

Brown, H. S., de Jong, M., Levy, D. L., 2009b. Building institutions based on information disclosure: lessons from GRI's sustainability reporting. Journal of Cleaner Production 6, 571-580.

Clarkson, P. M., Li, Y., Richardson, G. D., Vasvari, F. P., 2008. Revisiting the relation between environmental performance and environmental disclosure: An empirical analysis. Accounting Organizations and Society 4-5, 303-327. 
Petera, P. - Wagner, J.: Global Reporting Initiative (GRI) and its Reflections in the Literature.

Clarkson, P. M., Overell, M. B., Chapple, L., 2011. Environmental Reporting and its Relation to Corporate Environmental Performance. Abacus-a Journal of Accounting Finance and Business Studies 1, 27-60.

Dingwerth, K., Eichinger, M., 2010. Tamed Transparency: How Information Disclosure under the Global Reporting Initiative Fails to Empower. Global Environmental Politics 3, 74-96.

Etzion, D., Ferraro, F., 2010. The Role of Analogy in the Institutionalization of Sustainability Reporting. Organization Science 5, 1092-1107.

Evangelinos, K. I., Skouloudis, A., Nikolaou, I. E., Filho, W. L., 2009. An Analysis of Corporate Social Responsibility (CSR) and Sustainability Reporting Assessment in the Greek Banking Sector. In Idowu, Samuel O. - Filho, Walter Leal, eds. Professionals' Perspectives of Corporate Social Responsibility. Heidelberg: Springer, 157-173.

Gilbert, D. U., Rasche, A., 2008. Opportunities and Problems of Standardized Ethics Initiatives - Stakeholder Theory Perspective. Journal of Business Ethics 3, 755-773.

GRI, 2014. What is GRI? Global Reporting Initiative. Available from: <https://www.globalreporting.org/information/about-gri/what-is-

GRI/Pages/default.aspx>. [26 December 2014].

Herzig, Ch., Schaltegger, S., 2006. Corporate Sustainability Reporting: An Overview. In Schaltegger, S. - Bennett, M. - Burritt, R., eds. Sustainability Accounting and Reporting. Heidelberg: Springer, 301-324.

Chen, S., Bouvain, P., 2009. Is Corporate Responsibility Converging? A Comparison of Corporate Responsibility Reporting in the USA, UK, Australia, and Germany. Journal of Business Ethics 1, 299-317.

KPMG, 2011. KPMG International survey of corporate responsibility reporting 2011. Available from: <http://www.kpmg.com/PT/pt/IssuesAndInsights/ Documents/corporate-responsibility2011.pdf>. [26 December 2014].

KPMG, 2013. The KPMG Survey of Corporate Responsibility Reporting 2013. Available from: <http://www.kpmg.com/Global/en/IssuesAndInsights/ ArticlesPublications/corporate-responsibility/Documents/kpmg-survey-ofcorporate-responsibility-reporting-2013.pdf >. [26 December 2014].

Krajnc, D., Glavic, P., 2005. A model for integrated assessment of sustainable development. Resources Conservation and Recycling 2, 189-208.

Levy, D. L., Brown, H. S., de Jong, M., 2010. The Contested Politics of Corporate Governance: The Case of the Global Reporting Initiative. Business \& Society 1, 88-115.

Lozano, R., 2006. A tool for a Graphical Assessment of Sustainability in Universities (GASU). Journal of Cleaner Production 9-11, 963-972. 
Lozano, R., Huisingh, D., 2011. Inter-linking issues and dimensions in sustainability reporting. Journal of Cleaner Production 2-3, 99-107.

Lozano, R., 2013. Sustainability inter-linkages in reporting vindicated: a study of European companies. Journal of Cleaner Production, 57-65.

Manetti, G., Becatti, L., 2009. Assurance Services for Sustainability Reports: Standards and Empirical Evidence. Journal of Business Ethics 1, 289-298.

Manetti, G., 2011. The Quality of Stakeholder Engagement in Sustainability Reporting: Empirical Evidence and Critical Points. Corporate Social Responsibility and Environmental Management 2, 110-122.

Manetti, G., Toccafondi, S., 2012. The Role of Stakeholders in Sustainability Reporting Assurance. Journal of Business Ethics 3, 363-377.

Modapothala, J. R., Issac, B., Jayamani, E., 2010. Appraising the Corporate Sustainability Reports - Text Mining and Multi-Discriminatory Analysis. In Proceedings of the Innovations in Computing Sciences and Software Engineering, 489-494.

Moneva, J. M., Rivera-Lirio, J. M., Munoz-Torres, M. J., 2007. The corporate stakeholder commitment and social and financial performance. Industrial Management \& Data Systems 1-2, 84-102.

Mudd, G. M., 2008. Sustainability Reporting and Water Resources: a Preliminary Assessment of Embodied Water and Sustainable Mining. Mine Water and the Environment 3, 136-144.

Perez-Batres, L. A., Miller, V. V., Pisani, M. J., 2010. CSR, Sustainability and the Meaning of Global Reporting for Latin American Corporations. Journal of Business Ethics 2, 193-209.

Perez-Batres, L. A., Doh, J. P., Miller, V. V., Pisani, M. J., 2012. Stakeholder Pressures as Determinants of CSR Strategic Choice: Why do Firms Choose Symbolic Versus Substantive Self-Regulatory Codes of Conduct? Journal of Business Ethics 2, 157-172.

Rasche, A., 2009. Toward a Model to Compare and Analyze Accountability Standards - The Case of the UN Global Compact. Corporate Social Responsibility and Environmental Management 4, 192-205.

Rasche, A., 2010. The limits of corporate responsibility standards. Business Ethics: A European Review 3, 280-291.

Reynolds, M., Yuthas, K., 2008. Moral discourse and corporate social responsibility reporting. Journal of Business Ethics 1-2, 47-64.

Roca, L. C., Searcy, C., 2012. An analysis of indicators disclosed in corporate sustainability reports. Journal of Cleaner Production 1, 103-118.

Searcy, C., Buslovich, R., 2014. Corporate Perspectives on the Development and Use of Sustainability Reports. Journal of Business Ethics 2, 149-169. 
Petera, P. - Wagner, J.: Global Reporting Initiative (GRI) and its Reflections in the Literature.

Singh, R. K., Murty, H. R., Gupta, S. K., Dikshit, A. K., 2007. Development of composite sustainability performance index for steel industry. Ecological Indicators 3, 565-588

Skouloudis, A., Evangelinos, K., Kourmousis, F., 2009. Development of an Evaluation Methodology for Triple Bottom Line Reports Using International Standards on Reporting. Environmental Management 2, 298-311.

Skouloudis, A., Evangelinos, K., Kourmousis, F., 2010. Assessing non-financial reports according to the Global Reporting Initiative guidelines: evidence from Greece. Journal of Cleaner Production 5, 426-438.

Skouloudis, A., Evangelinos, K., Moraitis, S., 2012. Accountability and stakeholder engagement in the airport industry: An assessment of airports' CSR reports. Journal of Air Transport Management 1, 16-20.

Small, H., 1973. Co-citation in the Scientific Literature: A New Measure of the Relationship Between Two Documents. Journal of the American Society for Information Science 4, 265-269.

Thorne, L., Mahoney, L. S., Manetti, G., 2014. Motivations for issuing standalone CSR reports: a survey of Canadian firms. Accounting Auditing \& Accountability Journal 4, 686-714.

Waddock, S., 2008. Building a New Institutional Infrastructure for Corporate Responsibility. Academy of Management Perspectives 3, 87-108.

Willis, A., 2003. The role of the global reporting initiative's sustainability reporting guidelines in the social screening of investments. Journal of Business Ethics 3, 233-237. 